\title{
Spatial epidemiology of Toxoplasma gondii infection in goats in Serbia
}

\author{
Vitomir Djokić ${ }^{1}$, Ivana Klun ${ }^{1}$, Vincenzo Musella ${ }^{2}$, Laura Rinaldi ${ }^{3}$ Giuseppe Cringoli ${ }^{3}$, \\ Smaragda Sotiraki ${ }^{4}$, Olgica Djurković-Djaković ${ }^{1}$ \\ ${ }^{1}$ National Reference Laboratory for Toxoplasmosis, Centre for Parasitic Zoonoses, Institute for Medical \\ Research, University of Belgrade, Belgrade, Serbia; ${ }^{2}$ Department of Health Sciences, University Magna Gracia, \\ Catanzaro, Italy; ${ }^{3}$ Unit of Parasitology and Parasitic Diseases, Department of Veterinary Medicine and Animal \\ Productions, University of Naples Federico II, Naples, Italy; ${ }^{4}$ Veterinary Research Institute, National \\ Agricultural Research Foundation, Ionia, Thessaloniki, Greece
}

\begin{abstract}
A major risk factor for Toxoplasma gondii infection is consumption of undercooked meat. Increasing demand for goat meat is likely to promote the role of this animal for human toxoplasmosis. As there are virtually no data on toxoplasmosis in goats in Serbia, we undertook a cross-sectional serological study, including prediction modelling using geographical information systems (GIS). Sera from 431 goats reared in 143 households/farms throughout Serbia, sampled between January 2010 and September 2011, were examined for T. gondii antibodies by a modified agglutination test. Seroprevalence was $73.3 \%$ at the individual level and $84.6 \%$ at the farm level. Risk factor analysis showed above two-fold higher risk of infection for goats used for all purposes compared to dairy goats $(\mathrm{P}=0.012)$, almost seven-fold higher risk for goats kept as sole species versus those kept with other animals $(\mathrm{P}=0.001)$ and a two-fold lower risk for goats introduced from outside the farm compared to those raised on the farm $(\mathrm{P}=0.027)$. Moreover, households/farms located in centre-eastern Serbia were found to be less often infected than those in northern Serbia $(P=0.004)$. The risk factor analysis was fully supported by spatial analysis based on a GIS database containing data on origin, serology, land cover, elevation, meteorology and a spatial prediction map based on kriging analysis, which showed western Serbia as the area most likely for finding goats positive for T. gondii and centre-eastern Serbia as the least likely. In addition, rainfall favoured seropositivity, whereas temperature, humidity and elevation did not.
\end{abstract}

Keywords: Toxoplasma gondii, goats, seroprevalence, risk factors, geographical information systems, spatial analysis, Serbia.

\section{Introduction}

With its widest array of mammalian hosts including humans, Toxoplasma gondii may be the most successful parasite on Earth. This cosmopolitan protozoan, capable of infecting all warm-blooded animals and some cold-blooded animal species, has been estimated to infect one third of the global human population (Tenter et al., 2000). The organism's complex life cycle includes a sexual cycle completed in the intestines of members of the Felidae family (definitive hosts) resulting in the production of oocysts, while the asexual cycle involves encysted parasites circulating between prey and predator (the intermediate host). T. gondii

Corresponding author:

Olgica Djurković-Djaković

National Reference Laboratory for Toxoplasmosis

Centre for Parasitic Zoonoses, Institute for Medical Research

University of Belgrade

Dr. Subotica 4, P.O. Box 102, Belgrade 11129, Serbia

Tel. +381 112685 788; +381 112685 788; Fax +381 112643691

E-mail: olgicadj@imi.bg.ac.rs persists in the host by conversion from the proliferative tachyzoite stage into quiescent encysted bradyzoites, a mechanism controlled by the host immune response. Thus, although generally mild and self-limiting in immunocompetent individuals, T. gondii infection may cause life-threatening disease in the foetus and the immunosuppressed host.

Human infection occurs through ingestion of oocysts (via water, fruit and vegetables) or from tissue cysts present in infected meat. Goats, along with pigs and sheep, are the animal species mostly associated with human infection (Esteban-Redondo et al., 1999). Consumption of raw (unpasteurised) goat milk and milk products (e.g. cheese) has been linked to toxoplasmosis in humans and pigs (Skinner et al., 1990; Dubey 2009; Jones et al., 2009). Tachyzoites have been experimentally shown to survive in goat milk 37 days at $+4{ }^{\circ} \mathrm{C}$ (Walsh et al., 1999).

One study showed that $33 \%$ of milk samples from seropositive goats are positive for T. gondii DNA, a rate that increases with age (Spišák et al., 2010). As obligate herbivores, goats become infected by inges- 
tion of oocysts and toxoplasmosis is an important cause of foetal loss in this species. In pregnant goats, a primary infection may lead to placental and foetal infection resulting in foetal death and resorption, abortion or stillbirth (Dubey et al., 1985a). There is a body of data on the seroprevalence of toxoplasmosis in goats throughout the world with values ranging from $0 \%$ in Pakistan (Zaki, 1995) and $4 \%$ in Maranhao, Brazil (Moraes et al., 2011) to as high as $77 \%$ in France (Chartier et al., 1997) and $30-100 \%$ in Poland (Czopowicz et al., 2011). Interestingly, T. gondii infection in goats seems to be more prevalent in Europe than in Asia, Africa and South America with seroprevalence rates above $60 \%$ being reported in some European countries, including the Czech Republic, Spain and, more recently, Austria (Hejliček and Literak, 1994; Rodriguez-Ponce et al., 1995; Edelhofer and Prossinger, 2010).

Goats are traditionally an important source of meat and milk in many developing countries, but the last few decades have seen increased demand for goat products in developed countries as well. In the United States of America, some 850,000 goats are slaughtered annually for food and this number is expected to grow (Hill and Dubey, 2013). Likewise, in Serbia, as in Europe in general, the number of goats and goat farms is constantly increasing in the last decades. Currently, the number is estimated at between 80,000-100,000 goats.

The fact that goats constitute a significant infection reservoir, along with the increasing market share of goat products coupled with the presumption, common in some cultures, that goat milk should be consumed raw (unpasteurised) as well as current practices of "healthy eating", which often includes undercooking of meat, all contribute to the likely increased role of goats in human toxoplasmosis. However, there are virtually no data on toxoplasmosis in goats in Serbia. Therefore, a cross-sectional serological survey was conducted in order to: (i) determine the prevalence of T. gondii in Serbian goats; (ii) identify risk factors for infection; (iii) perform spatial analysis and prediction modelling using geographical information systems (GIS).

\section{Materials and methods}

\section{Study area}

The study covered all of Serbia, a land-locked country on the Balkan Peninsula, covering $77,512 \mathrm{~km}^{2}$. According to the CORINE Land Cover (http:// www.eea.europa.eu/publications/COR0-landcover) $34,473 \mathrm{~km}^{2}$ is agricultural land, $29,682 \mathrm{~km}^{2}$ covered by forests and semi natural areas, $2,606 \mathrm{~km}^{2}$ built-up areas and the rest wetlands and water bodies. As seen in Fig. 1, Serbia can be divided into northern, western and centre-eastern geographical regions (CE) plus the Belgrade district. The province of Vojvodina in the North has a typical continental climate and is mainly

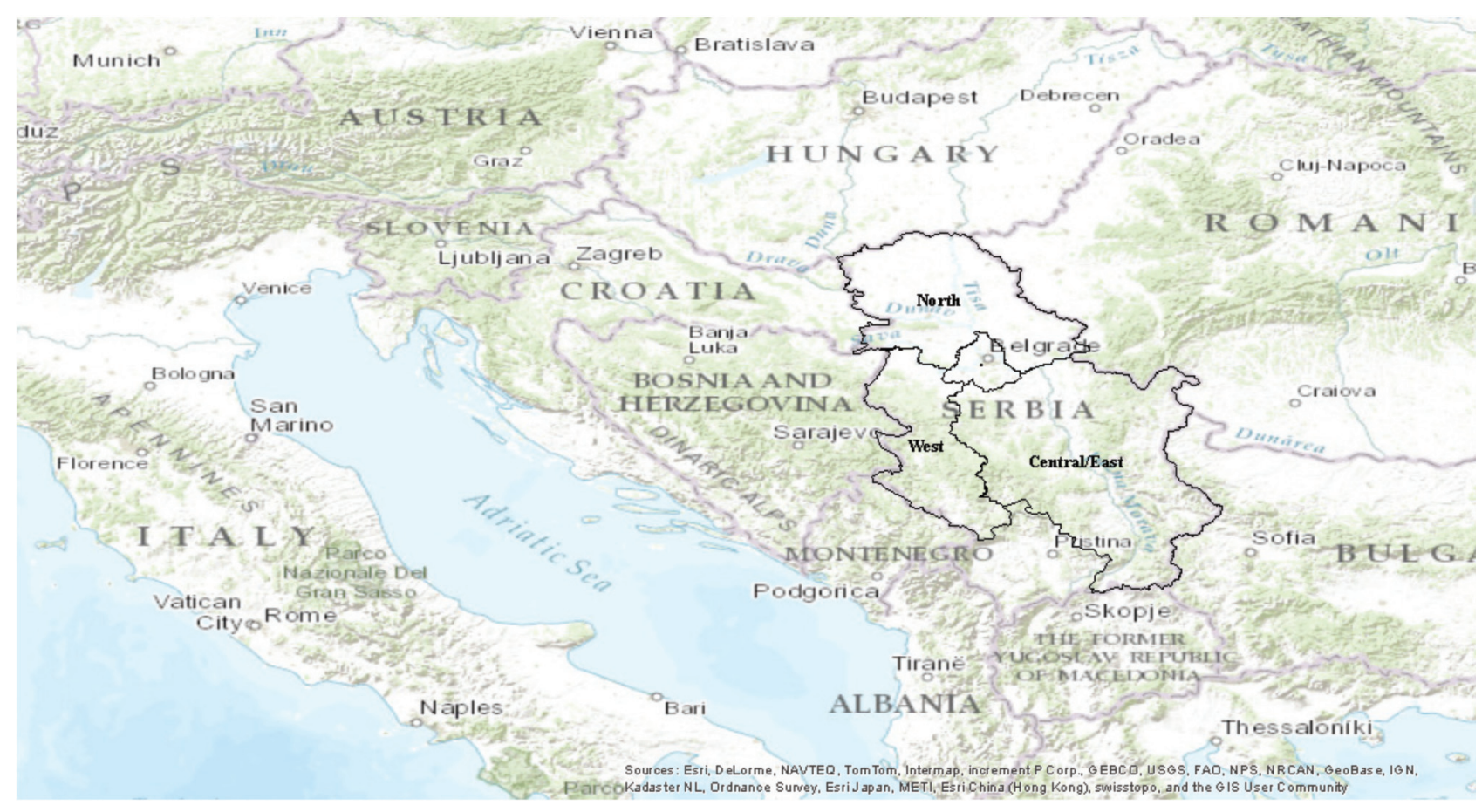

Fig. 1. Location map of Serbia with its four regions marked out. 
made up of agricultural plains north of the Sava and Danube rivers. While both the western and CE regions have a milder continental climate and are mostly characterised by agricultural river plains and forests, the western region is hilly to mountainous, and has more rainfall and humidity. The Belgrade district, set on the estuary of the Sava River into the Danube, is an administrative rather than a geographical region.

\section{Study population and sampling}

The study was conducted on a total of 431 goats reared in 143 households/farms throughout Serbia (Fig. 2). This sample size was calculated based on both a previous study in ruminants, which showed a seroprevalence of $76 \%$ in cattle and $84 \%$ in sheep (Klun at al., 2006), and a pilot study on 194 goats, which showed a prevalence of $82 \%$ (Klun et al., 2010). Thus, the sample size for an expected prevalence of at least $70 \%$ at the $5 \%$ absolute precision level for a $95 \%$ confidence interval (CI) was calculated at 323 animals (Thrusfield, 2005). Sampling of households/farms was representative of the different geographical areas of Serbia in relation to their size as follows: northern Serbia $(\mathrm{n}=51)$, western Serbia $(\mathrm{n}=15)$, CE $(\mathrm{n}=71)$ and the Belgrade district $(n=6)$.

According to the national goat and sheep database established by the Ministry for Agriculture, Forestry and Water Management (MAFWM), goats are kept on a total of 16,096 farms (Fig. 2). These include a multitude of households owning small flocks of goats (up to 10 ), which actually comprise $95 \%$ of all farms and are here defined as "household farms". A limited number of larger operations usually owning several dozen animals, representing $5 \%$ of all goat-rearing facilities, are here referred to as "farms". Most animals (64.3\%, 277/431) in the study sample were from household farms $(86.7 \%, 124 / 143$ households), which accurately reflects the state of goat rearing in Serbia, i.e. households rear $67 \%$, whereas the farms rear $33 \%$ of all goats in the country.

Blood samples were mostly collected between January and December $2010(\mathrm{n}=362)$, whereas an additional 69 samples were collected from western and CE Serbia in September 2011. The 2010 samples were obtained from the serum collection for the national brucellosis-testing programme, whereas the additional samples were obtained at the households/farms through the help of local veterinarians. Once at the laboratory, blood samples were centrifuged (400 g for $20 \mathrm{~min}$ ) and the obtained serum samples stored at $-20^{\circ} \mathrm{C}$ pending analysis.

\section{Collection of epizootiological data}

Data on potential risk factors including region, herd size, gender, age, origin, purpose, husbandry, presence of other livestock, presence of cats, feeding

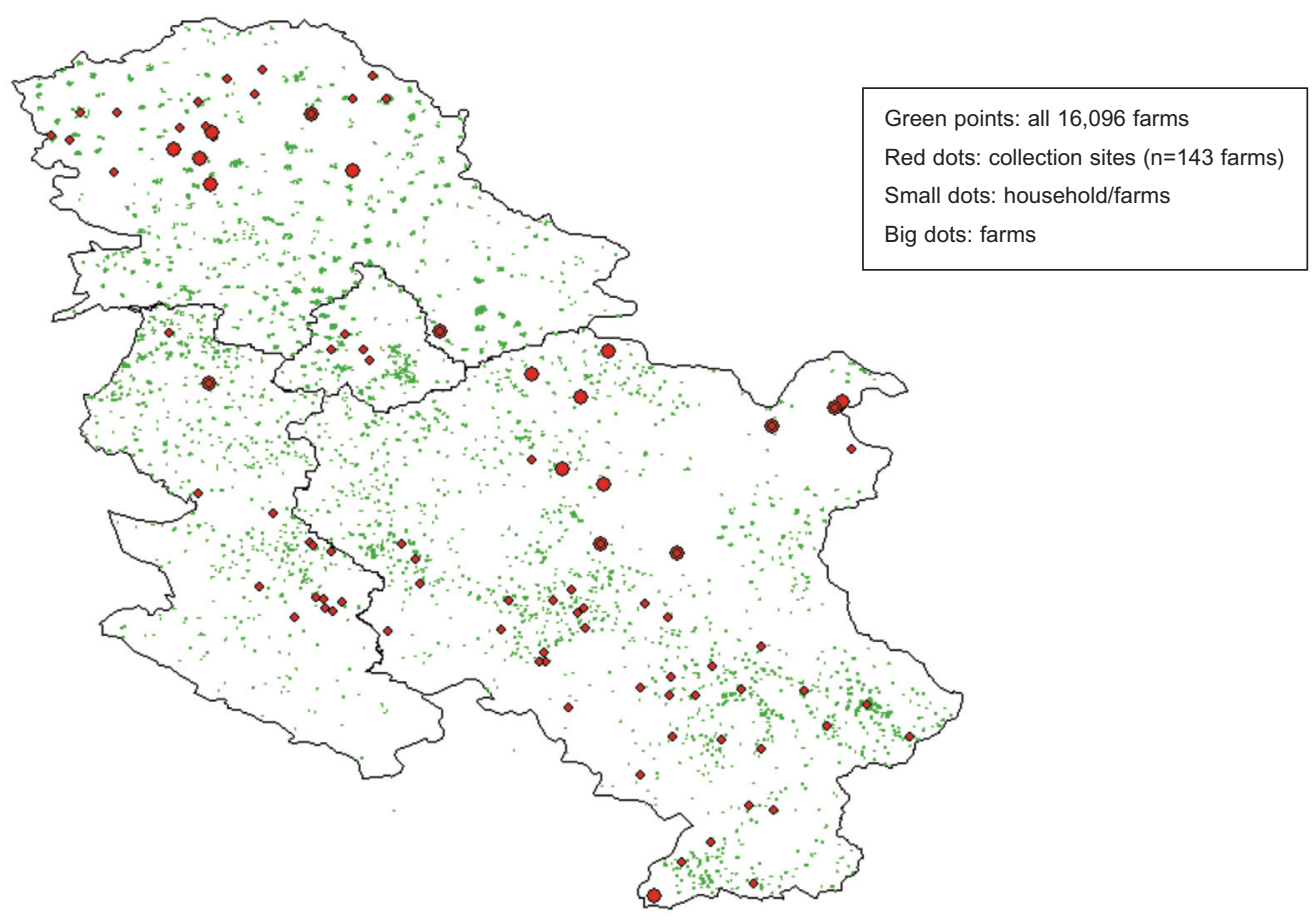

Fig. 2. Goat farm polulation and collection sites in the four regions of Serbia. 
and watering habits, breeding, health status and last year's health history, were obtained by means of a standardised questionnaire, which was filled in for each animal through a telephone interview with the owner or the local veterinarian. Ownership of each animal was determined by the ear tag number through the MAFWM national goat and sheep database. Some animals could not be traced and a few owners were not cooperative, so completed questionnaires were only available for 372 (86.3\%) animals from 100 (69.9\%) households/farms from all four regions.

Animals were classified by gender and by age as either young $(<1$ year) or adults ( $>1$ year). The origin of the animals was noted as those raised on a household/farm or introduced from elsewhere. According to purpose, goats were categorised into those used for milk and cheese production versus all other purposes (milk, cheese and meat production, breeding, companion/pet animals). The herd size was defined as previously described, either as small households $(\leq 10$ animals) or farms (>10 animals). The farms were categorised according to the type of housing into "stable only" (total confinement), "stable with access to outside pen" (partial confinement) and "stable with access to pasture" (with or without access to pen). According to the presence of other animals on the household/farm, categories included those that keep only goats, those that also keep other ruminants and/or horses, and those that also own pigs, dogs, chicken and other small animals. Presence of cats was noted dichotomously (yes/no), although the responses cannot be taken as absolutely reliable since cats are generally present in farms in Serbia and even when not owned by a particular goat-keeper, the presence of stray or neighbourhood cats cannot be ruled out. As to the feeding practices, goats were categorised into those are given food in a manger with or without trough, and those that are also fed by pasture. The watering practices were categorised as farms with regular tap water and farms supplied by a local well, river or stream. The questionnaire also contained information on whether animals had offspring and whether any had shown signs of clinical illness in the year prior to sample collection.

\section{Serology}

Detection of $T$. gondii antibodies was performed by the modified agglutination test (MAT) as described by Dubey and Desmonts (1987), which is considered the test of choice for the detection of T. gondii antibodies in animals (Dubey et al., 1985b; Klun et al., 2006). The antigen was kindly provided by the Centre National de Référence de la Toxoplasmose, Reims, France (Isabelle Villena). The starting dilution was 1:25 and all sera positive at that level or higher were considered positive.

\section{Statistical analysis}

All statistics were performed using the SPSS version 11.5 statistical package (SPSS Inc.; Chicago, USA). First, a univariate analysis of the influence of the different independent categorical variables on the T. gondii serological status (positive/negative) was performed by a $\chi^{2}$ test. Variables associated with positivity at $\mathrm{P} \leq 0.1$ at the $95 \%$ confidence level were tested for colinearity and included in a multivariate logistic regression model. Overall fit of the logistic regression model was assessed by the Hosmer-Lemeshow goodness-of-fit statistics (1989). Results are presented as adjusted odds ratios (OR) with $95 \%$ confidence intervals (CI). The level of significance was $5 \%$.

All 16,096 farms in the country were first georeferenced (Fig. 2) according to the WGS 1984 system (http://www.oosa.unvienna.org/pdf/icg/2012/template/WGS_84.pdf). Next, a GIS database containing data on the study population $(n=431)$, including origin, serological test results, land cover and climatic data, was generated using ArcGIS version 10.0 GIS software (ESRI; Redlands, USA). Each animal was georeferenced individually. Meteorological data including average annual temperature, rainfall and humidity for 2010 were taken from the 2010 annual report published by the National Meteorological Service (RHSS, 2011). A buffer zone of $10 \mathrm{~km}$ in diameter (chosen as one which contained all the study animals) was constructed around each of the 92 meteorological stations in the country. Meteorological data from stations with buffers containing study samples that were also at the same approximate elevation as the neighbouring farms $(n=54)$ were used for the analysis. These data together with the serological results were interpolated on a raster dataset by kriging and the geostatistical analyst tool to assess the uncertainty of the predictions derived from the measures of relationship in the samples based on sophisticated weighted average techniques (Laslett, 1994). All examined animals were taken into account for the analysis, regardless of repetition of coordinates when occurred. The best model was fit with an ordinary type of prediction without transformations and no order of trend 
removal. The final spatial prediction map was constructed based on a semivariogram calculated automatically with a major range among parameters of 1.946 degrees, with 12 lags and lag size of 0.24 . Predicted values were extrapolated on the map of all goat farms/households in Serbia.

\section{Results}

\section{Seroprevalence}

The overall seroprevalence of T. gondii infection in the goats (Table 1 ) was $73.3 \%(316 / 431)$, the highest in the Belgrade district (93.7\%) and the lowest in CE Serbia $(62.6 \%)$. Considering a farm positive if a single animal tested positive, the overall seroprevalence at the farm level was $84.6 \%$.

\section{Risk factors}

Risk factor analysis was performed on 372 animals for which the questionnaires were complete. Univariate analysis showed that a number of variables, such as age, husbandry, purpose, feeding practices, watering practices, origin, presence of other animals and the region of farm location, were associated with positive serology for T. gondii (Table 2). Since high colinearity was detected between "husbandry" and "feeding practices" (Cramer's V coefficient of 0.88), only the variable with the higher effect size ("husbandry") was included in the logistic regression analysis; thus the final multivariate model included seven variables. Hosmer-Lemeshow goodness-of-fit was 0.553 with $75.5 \%$ of correct prediction.

As seen in Table 3, the risk of infection was increased above two-fold (2.22) in goats used for all purposes versus those exclusively used for milk and cheese production $(\mathrm{P}=0.012)$, and almost seven-fold (6.64) in goats kept as sole species on a farm, versus those kept at a household/farm together with fowl, pigs, dogs and/or cats $(\mathrm{P}=0.001)$. On the other hand, a protective effect was shown for household/farm location in CE compared with northern Serbia $(\mathrm{P}=0.004)$, and for goats introduced from the outside compared to those raised on the farm $(\mathrm{P}=0.027)$. Although age above 1 year was shown to have a protective effect $(\mathrm{OR}=0.097, \mathrm{P}=0.030)$ compared to younger ages, this finding may be biased by the miniscule proportion $(4 \%, 16 / 372)$ of kids versus older animals.

\section{Spatial analysis}

Association between meteorological data and seroprevalence is visualised in Fig. 3. It can be seen that seronegativity is associated with lower rainfall within CE Serbia, whereas seropositivity is associated with higher rainfall, particularly in western Serbia (Fig. 4). Regarding elevation, more seropositive animals were found at lower average elevations (hilly areas) stretching from western Serbia to the central and southern parts of CE Serbia. No influence was seen for humidity and temperature.

A spatial analysis of seroprevalence of toxoplasmosis in goats was performed in ArcGIS version 10.0 using ordinary kriging without the nugget effect, because of the high seroprevalence. The constant mean assumption for the spatial mean surface was selected based on visual inspection of the empirical semivariogram, which levelled out almost perfectly. Taking into account unequal region sizes, the analysis predicted, some intra-regional differences notwithstanding, the greatest chance of finding goats testing positive for T. gondii in western Serbia (61-100\% probability), followed by northern Serbia (31-100\% probability) and the Belgrade district (71-100\% probability). CE Serbia had the lowest chance of seropositivity (0$100 \%$ probability), while the highest was seen in the

Table 1. Seroprevalence of T. gondii infection in goats at the individual and at the farm level in the four Serbian regions.

\begin{tabular}{|c|c|c|c|c|c|c|}
\hline \multirow[b]{2}{*}{ Region } & \multicolumn{3}{|c|}{ Individual level } & \multicolumn{3}{|c|}{ Farm level } \\
\hline & Tested & Prevalence $(\%)$ & $95 \% \mathrm{CI}^{*}$ & Tested & Prevalence $(\%)^{* * *}$ & $95 \% \mathrm{CI}^{*}$ \\
\hline North & 120 & 77.5 & $70.0-85.0$ & 51 & 88.2 & $79.3-97.0$ \\
\hline West & 73 & 87.7 & $80.2-95.2$ & 15 & 100 & 100 \\
\hline Central/East & 206 & 62.6 & $56.0-69.2$ & 71 & 77.5 & $67.8-87.2$ \\
\hline Belgrade & 32 & 93.7 & $85.3-100$ & 6 & 100 & 100 \\
\hline Total & 431 & 73.3 & $69.1-77.5$ & 143 & 84.6 & 78.7- 90.5 \\
\hline
\end{tabular}

*95\% confidence intervals; $*$ a farm was considered positive if at least one animal tested positive. 
Table 2. Univariate analysis of the prevalence of T. gondii-specific antibodies in goats $(n=372)$ in Serbia according to zoographic and farm management characteristics.

\begin{tabular}{|c|c|c|c|c|c|c|}
\hline Variable & $\mathrm{N}$ & Prevalence (\%) & $95 \% \mathrm{CI}^{\mathrm{a}}$ & $\mathrm{OR}^{\mathrm{b}}$ & $95 \% \mathrm{CI}^{\mathrm{a}}$ & P-value \\
\hline Gender & & & & & & 0.440 \\
\hline Male & 28 & 64.3 & $40.7-87.9$ & 1.00 & & \\
\hline Female & 344 & 71.2 & $63.7-78.7$ & 1.37 & $0.61-3.08$ & \\
\hline Age (years) & & & & & & 0.071 \\
\hline$<1$ & 16 & 93.8 & 48.1-100 & 1.00 & & \\
\hline$>1$ & 356 & 70.1 & $62.8-77.3$ & 0.15 & $0.02-1.17$ & \\
\hline Herd size & & & & & & 0.242 \\
\hline$\leq 10$ & 223 & 73.1 & $63.6-82.6$ & 1.00 & & \\
\hline$>10$ & 150 & 67.3 & $56.6-78.0$ & 0.76 & $0.48-1.19$ & \\
\hline Husbandry & & & & & & 0.002 \\
\hline Stable & 131 & 59.5 & $49.4-69.6$ & 1.00 & & \\
\hline Access to outside pens & 79 & 74.7 & $58.3-91.0$ & 2.00 & $1.08-3.71$ & \\
\hline Access to pasture & 162 & 77.8 & 65.9-89.7 & 2.38 & $1.43-3.96$ & \\
\hline Principal activity & & & & & & $<0.001$ \\
\hline Dairy production & 258 & 64.7 & $56.9-72.6$ & 1.00 & & \\
\hline Additional use $^{c}$ & 114 & 84.2 & $68.8-99.6$ & 2.91 & $1.65-5.11$ & \\
\hline Feeding practice & & & & & & 0.009 \\
\hline Manger/manger and trough & 203 & 65.0 & $56.1-73.9$ & 1.00 & & \\
\hline Manger and trough, pasture & 169 & 77.5 & $65.9-89.2$ & 1.85 & $1.17-2.94$ & \\
\hline Watering practice & & & & & & 0.001 \\
\hline Public water distribution & 232 & 64.2 & $56.0-72.4$ & 1.00 & & \\
\hline Public and/or well/lake/stream & 140 & 81.4 & $68.0-94.8$ & 2.44 & $1.48-4.04$ & \\
\hline Origin & & & & & & 0.020 \\
\hline Born on farm & 232 & 75.0 & $65.4-84.6$ & 1.00 & & \\
\hline Outside source & 140 & 63.6 & $53.1-74.0$ & 0.58 & $0.37-0.92$ & \\
\hline Presence of other animals & & & & & & 0.003 \\
\hline Fowl/pigs/dogs/cats & 306 & 66.7 & $59.3-74.1$ & 1.00 & & \\
\hline Ruminants, horses & 47 & 84.2 & $60.3-100$ & 2.67 & $0.76-9.36$ & \\
\hline Exclusively goats & 19 & 91.5 & $50.6-100$ & 5.37 & $1.88-15.39$ & \\
\hline Breeding (kid) & & & & & & 0.413 \\
\hline Yes & 335 & 71.3 & $63.7-78.9$ & 1.00 & & \\
\hline No & 37 & 64.9 & $44.1-85.6$ & 1.35 & $0.66-2.76$ & \\
\hline Clinically treated last year & & & & & & 0.357 \\
\hline Yes & 15 & 60.0 & 29.9-90.1 & 1.00 & & \\
\hline No & 357 & 71.1 & $63.8-78.5$ & 0.61 & $0.21-1.75$ & \\
\hline Presence of cats & & & & & & 0.106 \\
\hline Yes & 321 & 69.2 & $61.6-76.7$ & 1.00 & & \\
\hline No & 51 & 80.4 & $58.5-100$ & 0.55 & $0.26-1.14$ & \\
\hline Land cover & & & & & & 0.166 \\
\hline Agricultural cover & 149 & 75.8 & $63.7-87.9$ & 1.00 & & \\
\hline Forests/seminatural areas & 126 & 69.1 & $57.1-81.0$ & 0.71 & $0.42-1.21$ & \\
\hline Built up areas & 97 & 64.9 & $52.1-77.8$ & 0.59 & $0.34-1.03$ & \\
\hline Region & & & & & & $<0.001$ \\
\hline North & 102 & 74.5 & 60.1-88.9 & 1.00 & & \\
\hline West & 69 & 86.9 & $66.5-100$ & 2.28 & $0.99-5.23$ & \\
\hline Central/East & 176 & 59.1 & $50.4-67.8$ & 0.49 & $0.29-0.85$ & \\
\hline Belgrade & 25 & 92.0 & $56.1-100$ & 3.93 & $0.87-17.84$ & \\
\hline Total & 372 & 70.7 & $67.1-74.3$ & & & \\
\hline
\end{tabular}

a95\% confidence interval; bodds ratio; cdairy and meat production, breeding, companion animals or pet animals. 
Table 3. Final logistic regression model of the risk factors for T. gondii infection in goats in Serbia.

\begin{tabular}{|c|c|c|c|}
\hline Variable & Adjusted OR* & $95 \% \mathrm{CI}^{\mathrm{a}}$ & P-value \\
\hline \multicolumn{4}{|l|}{ Animal age (years) } \\
\hline$<1$ & 1.00 & & \\
\hline$>1$ & 0.10 & $0.01-0.80$ & 0.030 \\
\hline \multicolumn{4}{|l|}{ Principal farm activity } \\
\hline Dairy production & 1.00 & & \\
\hline Additional uses & 2.22 & $1.19-4.15$ & 0.012 \\
\hline \multicolumn{4}{|l|}{ Animal origin } \\
\hline Born on farm & 1.00 & & \\
\hline Outside source & 0.56 & $0.34-0.94$ & 0.027 \\
\hline \multicolumn{4}{|c|}{ Presence of other animals } \\
\hline Fowl/pigs/dogs/cats & 1.00 & & \\
\hline Ruminants, horses & 1.50 & $0.34-6.51$ & 0.590 \\
\hline Goats only & 6.64 & $2.24-19.68$ & 0.001 \\
\hline \multicolumn{4}{|l|}{ Region } \\
\hline North & 1.00 & & \\
\hline West & 2.03 & $0.85-4.87$ & 0.111 \\
\hline Central/East & 0.43 & $0.24-0.76$ & 0.004 \\
\hline Belgrade & 4.19 & $0.88-20.02$ & 0.073 \\
\hline
\end{tabular}

*odds ratio; * *95\% confidence intervals.

centre of the country (Fig. 4). In western Serbia, the probability was constant throughout the region, but the probability of finding positive animals in northern Serbia increased in the north $(31 \%)$ south direction to reach $100 \%$ at the boundary with western Serbia and the Belgrade district. Within CE Serbia, a decreasing trend in the eastern and southern directions was noted, so that the probability of seropositivity was only $0-30 \%$ in a whole third of the region. This agrees perfectly with the results of the risk factor analysis, which showed a protective effect for household/farm location in CE versus northern Serbia.
A

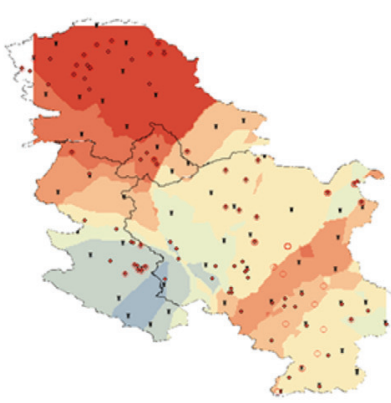

C

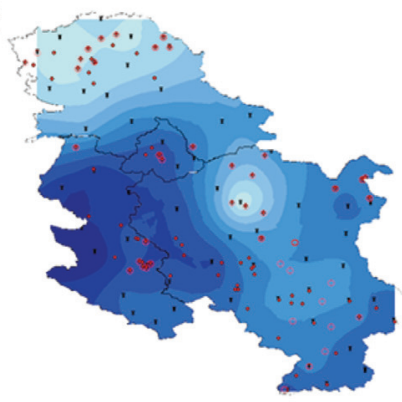

B

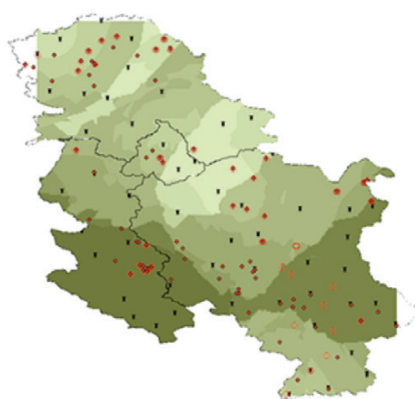

$\mathrm{D}$

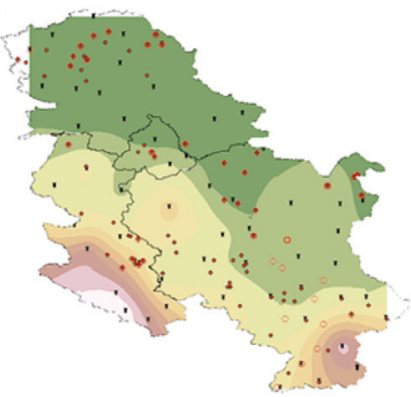

I Meteorological stations

Negative

Positive

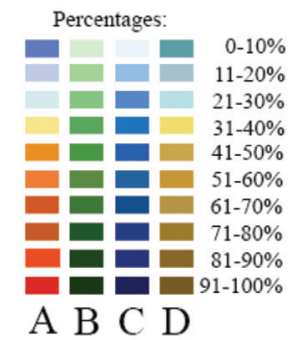

Fig. 3. Farm prevalence of T. gondii in goats in relation to meteorological and environmental data in Serbia for the year 2011. $\mathrm{A}=$ temperature; $\mathrm{B}=$ humidity; $\mathrm{C}=$ rainfall; $\mathrm{D}=$ elevation $(0 \%=$ lowest and $100 \%=$ highest recorded value $)$. Cut-off points of the colour shading are the $5 \%, 50 \%$ and $95 \%$ quantiles of the empirical distribution. 


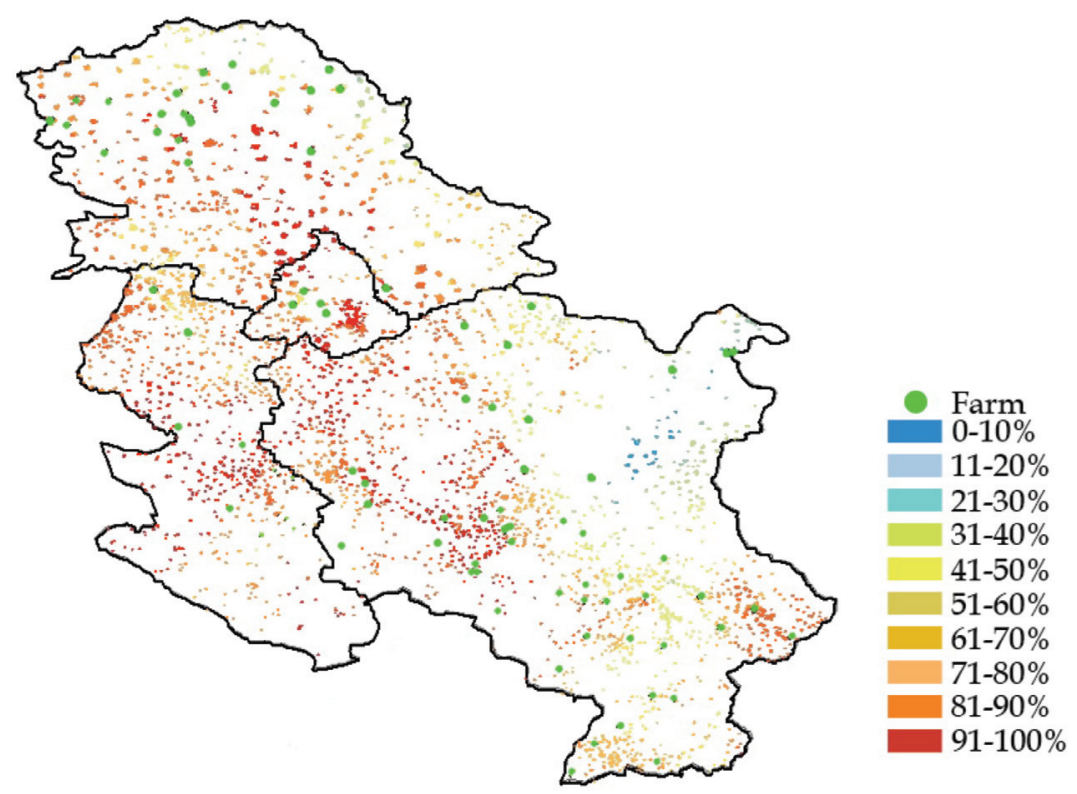

Fig. 4. Spatial prediction of seroprevalence of T. gondii infection in Serbian goat farms. Isopleth map based on kriging analysis (cutoff points of the colour scale are the $5 \%, 50 \%$ and $95 \%$ quantiles of the empirical distribution).

\section{Discussion}

The T. gondii prevalence in goats in Serbia detected in this study, both at the individual level $(73.3 \%)$ and at the farm level $(84.6 \%)$, is higher compared to recent data from other European countries. For example, a study in Portugal showed a prevalence of $18.5 \%$ at the individual level with the same agglutination test as we used (Lopes et al., 2013), whereas a survey in Greece based on enzyme - linked immunosorbent assay (ELISA), found a prevalence of $31 \%$ (Tzanidakis et al., 2012). The highest prevalence at the individual level $(52.8 \%)$ outside Serbia was recently reported in Romania (Iovu et al., 2012). On the other hand, high farm prevalence rates are common. A study in Poland showed a $100 \%$ farm level with a $30-100 \%$ prevalence at the individual level (Czopowicz et al. 2011), while in Norway, despite a $17 \%$ prevalence at the individual level, the farm prevalence was $75 \%$ (Stormoen et al., 2012) and a prevalence of $25.1 \%$ for animals and $72.2 \%$ for farms has been reported from Spain (Garcia-Bocanegra et al., 2013).

In view of the findings mentioned above, it is surprising that we found some uninfected farms (Table 1) despite a very high prevalence at the individual level. However, our findings agree with the prevalence of T. gondii in other ruminants in Serbia; e.g. $76 \%$ and $84 \%$ in cattle and sheep, respectively, reported by Klun et al. (2006), a finding that might reflect environmental as well as zoohygienic and zootechnical conditions under which animals are reared for meat. In this context, it was very important to examine the risk factors for goat infection. Whereas a number of factors, including age, husbandry, type of farm (meat or dairy), feeding practices, watering practices, origin, presence of other animals and regional location, were all associated with T. gondii seropositivity, keeping goats for all purposes and keeping goats only, were T. gondii infection risk factors. Conversely, farm location in CE Serbia and introduction of outside animals were factors protective against infection.

An increased risk of T. gondii infection in all-purpose compared to dairy goats may be expected and has often been reported (García-Bocanegra et al., 2013; Santos et al., 2012; Zewdu et al., 2013). Allpurpose animals tend to be kept in small household farms where zoohygienic vigilance is generally lower than on farms that exclusively rear dairy goats since the latter are generally commercially oriented, larger and run with higher vigilance. Although this explanation seems at first glance discrepant with the finding of an increased risk of infection in case of keeping goats only on the farm (as opposed to their cohabitation with other species), it is likely that if there is a source of infection in a large $(\mathrm{r})$ commercial goat-breeding facility, more animals would be exposed. An increased risk of infection was shown in goat kids compared to animals older than 1 year, a result that could have arisen from the tiny proportion of young animals in the study sample $(4 \%, 16 / 372)$. The perhaps surprising 
protective effect shown for goats introduced from outside the farm versus those raised on the farm may be explained by the possibility the introduced goats originated from farms or regions of Serbia with a lower seroprevalence. Indeed, seropositivity related to a lack of replacements in the preceding year has been reported (Mainar et al., 1996).

The protective effect for household/farm located in CE versus northern Serbia was corroborated with the spatial analysis, which predicted the greatest chance of finding T. gondii positive goats in western Serbia and the lowest in CE Serbia, especially in its southeastern part. This prediction, based on kriging, also allowed us to predict the serological status of animals in unsampled areas, since this approach takes place within the borders of a spatial linear model (Berke, 2004). Considering this spatial correlation, our prediction model is valid for the geometrical rectangle formed among the most northern, eastern, southern, and western sampling points on the territory of Serbia.

The concordance between higher prevalence and rainfall in the western and $\mathrm{CE}$ regions could be explained by the fact that oocysts have a longer viability in damp soil, a fact that has been experimentally proven by Lèlu et al. (2012) and also observed in the field (Dumètre and Dardé, 2003). Additionally, the prediction map showed that the chances of finding T. gondii positive goats in northern Serbia near the border with Romania are between $51 \%$ and $60 \%$, which perfectly agrees with the seroprevalence of $52.8 \%$ determined by Iovu et al. (2012) in the region of Romania bordering Serbia. Also, the chances of finding T. gondii positive goats decrease from western Serbia in the eastern and southern directions to values between $0 \%$ and $60 \%$, whereas in northern Greece a seroprevalence of $30.7 \%$ has been reported (Tzanidakis et al., 2012). Unfortunately, these data are not available for the region in-between (the Former Yugoslav Republic of Macedonia.) Further field studies are needed to validate the presented prediction model, i.e. verify areas of lower environmental contamination.

\section{Conclusion}

The high prevalence of T. gondii infection in goats in Serbia reported here provides further evidence of extensive environmental contamination with this parasite. This requires strong preventive measures, including improvement of zootechnical and zoohygienic measures (e.g. specific rules for goat production aim- ing at better goat health). In addition, farmers should be recommended to frequently introduce unexposed new stock and encouraged to raise goats together with other species. The results of the spatial prediction model may serve as a recommendation for establishing new farms in the CE region.

\section{Acknowledgement}

This work was supported by grant III 41019 from the Ministry of Education, Science and Technological Development of the Republic of Serbia, and COST Action FA0805 (CAPARA).

\section{References}

Berke O, 2004. Exploratory disease mapping: kriging the spatial risk function from regional count data. Int J Health Geogr 3, 18. Chartier C, Beziaud E, Buzoni-Gatel D, 1997. Enquete sero-epidemiologique sur les avortements infectieux des caprins en region Poitou-Charentes. Rev Med Vet (Toulouse) 148, 489496.

Czopowicz M, Kabaa J, Szalus-Jordanowb O, Nowickia M, Witkowskia L, Frymusb T, 2011. Seroprevalence of Toxoplasma gondii and Neospora caninum infections in goats in Poland. Vet Parasitol 178, 339-341.

Dubey JP, 2009. Toxoplasmosis of animals and humans. CRC Press, 313 pp.

Dubey JP, Desmonts G, 1987. Serological responses of equids fed Toxoplasma gondii ocysts. Equine Vet J 19, 337-339.

Dubey JP, Desmonts G, Antunes F, McDonald C, 1985a. Serologic diagnosis of toxoplasmosis in experimentally infected pregnant goats and transplacentally infected kids. Am J Vet Res 46, 1137-1140.

Dubey JP, Desmonts G, McDonald C, Walls KW, 1985b. Serologic evaluation of cattle inoculated with Toxoplasma gondii: comparison of Sabin-Feldman dye test and other agglutination tests. Am J Vet Res 46, 1085-1088.

Dumètre A, Dardé ML, 2003. How to detect Toxoplasma gondii oocysts in environmental samples? FEMS Microbiol Rev 27, 651-661.

Edelhofer R, Prossinger H, 2010. Infection with Toxoplasma gondii during pregnancy: seroepidemiological studies in Austria. Zoonoses Public Health 57, 18-26.

Esteban-Redondo I, Maley SW, Thomson K, Nicoll S, Wright S, Buxton D, Innes EA, 1999. Detection of Toxoplasma gondii in tissues of sheep and cattle following oral infection. Vet Parasitol 86, 155-171.

García-Bocanegra I, Cabezón O, Hernández E, Martínez-Cruz MS, Martínez-Moreno A, Martínez-Moreno J, 2013. Toxoplasma gondii in ruminant species (cattle, sheep, and goats) from Southern Spain. J Parasitol 99, 438-440. 
Hejliček K, Literak I, 1994. Incidence and prevalence of toxoplasmosis among sheep and goats in southern and western Bohemia. Acta Vet Brno 63, 145-150.

Hill DE, Dubey JP, 2013. Toxoplasma gondii prevalence in farm animals in the United States. Int J Parasitol 43, 107-113.

Hosmer D, Lemeshow S, 1989. Applied logistic regression. A much-cited recent treatment utilized in SPSS routines. New York: John Wiley and Sons.

Jones JL, Dargelas V, Roberts J, Press C, Remington JS, Montoya JG, 2009. Risk factors for Toxoplasma gondii infection in the United States. Clin Infect Dis 49, 878-884.

Iovu A, Györke A, Mircean V, Gavrea R, Cozma V, 2012. Seroprevalence of Toxoplasma gondii and Neospora caninum in dairy goats from Romania. Vet Parasitol 186, 470-474.

Klun I, Bradonjić S, Djokić V, Djurković-Djaković O, 2010. Toxoplasma gondii infection in goats in Serbia (preliminary results). CAPARA $2^{\text {nd }}$ working groups workshop and management committee meeting, 29 Sep - 1 Oct 2010, Abstract book, p. 3.

Klun I, Djurković-Djaković O, Katić-Radivojević S, Nikolić A, 2006. Cross-sectional survey on Toxoplasma gondii infection in cattle, sheep and pigs in Serbia: seroprevalence and risk factors. Vet Parasitol 135, 121-131.

Laslett M, 1994. Kriging and splines: an empirical comparison of their predictive performance in some applications. J Am Stat Assoc 89, 391-409.

Lélu M, Villena I, Dardé ML, Aubert D, Geers R, Dupuis E, Marnef F, Poulle ML, Gotteland C, Dumètre A et al., 2012. Quantitative estimation of the viability of Toxoplasma gondii oocysts in soil. Appl Environ Microbiol 78, 5127-5132.

Lopes AP, Dubey JP, Neto F, Rodrigues A, Martins T, Rodrigues M, Cardoso L, 2013. Seroprevalence of Toxoplasma gondii infection in cattle, sheep, goats and pigs from the north of Portugal for human consumption. Vet Parasitol 193, 266-269.

Mainar RC, de la Cruz C, Asensio A, Domínguez L, VázquezBoland JA, 1996. Prevalence of agglutinating antibodies to Toxoplasma gondii in small ruminants of the Madrid region, Spain, and identification of factors influencing seropositivity by multivariate analysis. Vet Res Commun 20, 153-159.

Moraes LM, Raimundo JM, Guimarães A, Santos HA, Macedo Junior Gde L, Massard CL, Machado RZ, Baldani CD, 2011.
Occurrence of anti-Neospora caninum and anti-Toxoplasma gondii IgG antibodies in goats and sheep in western Maranhão, Brazil. Rev Bras Parasitol Vet 20, 312-317.

RHSS, 2011. Annual report 2010. Republic Hidrometeorological Service of Serbia, 20 pp.

Rodriguez-Ponce E, Molina JM, Hernandez S, 1995. Seroprevalence of goat toxoplasmosis on Grand Canary Island (Spain). Prev Vet Med 24, 229-234.

Santos Cde S, de Azevedo SS, Soares HS, Higino SS, Pena HF, Alves CJ, Gennari SM, 2012. Risk factors associated with Toxoplasma gondii seroprevalence in goats in the State of Paraíba, Brazil. Rev Bras Parasitol Vet 21, 399-404.

Skinner LJ, Timperley AC, Wightman D, Chatterton JMW, HoYen DO, 1990. Simultaneous diagnosis of toxoplasmosis in goats and goatowner s family. Scand J Infect Dis 22, 359-361. Spišák F, Turceková L, Reiterová K, Špilovská S, Dubinsky P, 2010. Prevalence estimation and genotypization of Toxoplasma gondii in goats. Biologia 65, 670-674.

Stormoen M, Tharaldsen J, Hopp P, 2012. Seroprevalence of Toxoplasma gondii infection in Norwegian dairy goats. Acta Vet Scand 54, 75-77.

Tenter AM, Heckeroth AR, Weiss LM, 2000. Toxoplasma gondii: from animals to humans. Int J Parasitol 30, 12171258.

Thrusfield M, 2005. Veterinary epidemiology. Blackwell Science, 610 pp. (third edition).

Tzanidakis N, Maksimov P, Conraths FJ, Kiossis E, Brozos C, Sotiraki S, Schares G, 2012. Toxoplasma gondii in sheep and goats: seroprevalence and potential risk factors under dairy husbandry practices. Vet Parasitol 190, 340-348.

Walsh CP, Hammond SE, Zajac AM, Lindsay DS, 1999. Survival of Toxoplasma gondii tachyzoites in goat milk: potential source of human toxoplasmosis. J Eukaryot Microbiol 46, 73-74.

Zaki M, 1995. Seroprevalence of Toxoplasma gondii in domestic animals in Pakistan. J Pak Med Assoc 45, 4-5.

Zewdu E, Agonafir A, Sisay Tessema T, Tilahun G, Girmay Medhin G, Vitale M, Di Marco V, Cox E, Vercruysse J, Dorny P, 2013. Seroepidemiological study of caprine toxoplasmosis in East and West Shewa zones, Oromia Regional state, Central Ethiopia. Res Vet Sci 94, 43-48. 